\title{
INTELLECTUAL DISABILITIES: COGNITION AND BEHAV- IOR - STRATEGY OF EDUCATION AND TREATMENT
}

\author{
Dragana Maćešić-Petrović, ${ }^{1, a, "}$ \\ Jasmina Kovačevića,** \\ Husnija Hasanbegovićb
}

Original scientific paper

Faculty of Special Education and Rehabilitation, University of Belgrade ${ }^{a}$

Faculty of Special Education and Rehabilitation, University of Tuzla ${ }^{b}$

Received: 08.02.2015

UDC: $376.1-056.34$

Accepted: 28.02.2015

$159.922 .76-056.34$

616.89-008

\begin{abstract}
This paper addresses different aspects of practical interventions with regard to education and rehabilitation of children with intellectual disabilities which can take place in schools or other rehabilitation settings. The outlined approach is based on the Bruner's concept of so-called growth sciences which include both the special education and the rehabilitation. The focus is on the theoretical, diagnostic, and rehabilitation strategy, based on the implementation of educational and treatment activities with this population of children. In the light of applied research we try to define interventions in education and rehabilitation of the children with mild intellectual disabilities. The sample was formed of 124 participants in school settings with regard to their cognitive and school achievement. With respect of these results we propose the educational and treatment strategies for these children.
\end{abstract}

Key words: attention, cognition, intellectual disabilities, education, treatment.

\section{INTRODUCTION}

This part of research try to formulate a concept of the diagnostic and rehabilitation basis of the methodology for treatment of the children with intellectual disabilities. Bearing in mind that education of children with intellectual disabilities should be subordinated to the needs of their personality, the following requirements were defined as the objectives of this research:

Definition of special (educational) diagnostics in the context of developmentally defined contents of teaching plans and programs;

Developmental definition of curricular content in the light of applied research;

Definition of treatment strategies with children with intellectual disabilities (Maćešić-Petrović, Japundža-Milisavljević, 2009).
This concepts arose from the need to rise above the fact that "those who were innovators in education were often non-educators " (Gaddes, 1985:12), but it is also a result of contemporary global efforts and trends that spouted from the Bruner's view that it is necessary to "align and unite all sciences which can contribute to the creation of a theory to facilitate cognitive development, enrich and strengthen the powers of human mind that are being developed, into the growth sciences which would, among others, include both education and psychology", and, we might add, special education and rehabilitation (Gaddes, 1985: 12,13).

\footnotetext{
Correspodence to:

Dragana Maćešić-Petrović, University of Belgrade, Faculty of Special Education and Rehabilitation, Visokog Stevana 2, 11000 Belgrade, Serbia.

E-mail: macesicd@yahoo.com

*Article is realized under the project"Kreiranje protokola za procenu edukativnih potencijala dece sa smetnjama u razvoju kao kriterijuma za izradu individualnih obrazovnih programa“, broj 179025, Ministarstvo za nauku i tehnološki razvoj, Beograd, 2011-2015, project manager prof.dr Jasmina Kovačević
} 
Taking into account Bruner's views with regard to developing a concept of growth sciences, we build our position in respect of the work with children with intellectual disabilities on the concept of "educational neuropsychology" as a concept that originated in the United States of America and resulted in establishment of a new scientific discipline whose study subject are children with developmental and learning disabilities, terminologically formulated as the concept of "Learning Disabilities" (Gaddes, 1985: 20).

According to Gaddes, educational neuropsychology is a separate scientific discipline based on a wide field of experimentally confirmed scientific knowledge which is of essential significance for understanding and treating children with cerebral lesions and the children with learning disabilities who have perceptive, cognitive and/or motor deficits (Gaddes, 1985). Some professional dilemmas relating to the question whether neuropsychology is relevant for education and training are clarified by the authors of this concept through three aspects of the validity of use of neuropsychological insights for understanding and treating learning disabilities:

1.This approach makes it possible to determine the locus and nature of cerebral dysfunction

2.Results of the use of educational diagnostics point to each individual child's educational strengths and weaknesses

3.Knowledge in this field makes it possible to formulate a suitable form of education and training of children with developmental and learning disabilities.

Gaddes underlines that the dilemma of the "territoriality of special education" was created artificially by a number of educational diagnosticians ${ }^{2}$ who are averse to incorporating neuropsychological insights and insights from related disciplines into the existing theoretical and practical frameworks of special education (Bojanin, 1986; Golden, 1987; Gillberg, 1992; Maćešić-Petrović, Japundža-Milisavljević, 2009).

This requires a more complex, higher level of personality understanding and points to the need to integrate the knowledge from related disciplines such as neuropsychology, psychiatry and psychology - as

\footnotetext{
${ }^{2}$ The term "educational diagnostician", according to the Gaddes concept, indicates an expert who, in the domain of special education, implements diagnostic methods and processes with the aim to determine the educational process and treatment of children with developmental and learning disabilities (38, p.18).
}

the sciences addressing the conditions of a suffering person, regardless of the cause of such suffering into the theoretical and practical work in education and training.

\section{OBJECTIVES}

In accordance with above observations and consistent with globally formulated objectives, this part of research was defined in three levels that include the elaboration of special (educational) diagnostics as a basis of development-based formulation of curricular content and rehabilitational role of the education of children with intellectual disabilities.

In connection with this, we highlight the viewpoints that have originated in our environment and which suggested that - in keeping with contemporary humanities, including special education and rehabilitation which is a science of man with developmental disabilities - knowledge from related disciplines should be incorporated into the existing system of scientific knowledge. We need to do this because it is necessary to do more than merely study the personality traits of persons with developmental disabilities and thus neglect the entirety of the personality.

\section{Diagnostic bases of the education and treatment of children with intellectual disabilities}

Developing curricula and syllabuses for educational work with children with developmental disabilities is a complex process determined by the definition and adjustment of the teaching content to the developmental characteristics and abilities of children included in the educational process. Therefore, in the process of curriculum and syllabus development, the issue of essential importance is the one pertaining to the dilemma what an individual can learn and to what extent such individual is capable of accepting the curricular content (Bailey, 2005).

This notion of ability and capacity of an individual for education is formulated in the English-speaking countries by the term "educable". Taking into account the need for as clear as possible identification of the child's capacity for education, the authors of this concept indicate the need to apply the so-called educational or special diagnostics in the process of education and teaching of children with intellectual disabilities. 
By application of tests and measuring instruments in the field of special (educational) diagnostics, the insight is gained into the development level and quality of the development of neuropsychological structures and abilities which are the basis of learning and cognitive achievement as well as social functioning of children with developmental disabilities.

Special or educational diagnostics includes standardized diagnostic procedures and measuring instruments that are based on the theoretical framework of growth oriented scientific disciplines established in the English-speaking countries. It is intended for all experts dealing with the development of children and their education, and primarily for special educators since it allows them to assess the development level and quality of those neuropsychological structures and functions which are the basis of learning, cognition, behavior and education, (Syzmanski, 1989; Dosen et al., 2001; Durston et al., 2007; Conroy et al., 2008; Craig, 2009).

At this point we should point out the Sidman \& Stoddard's standpoint as quoted by Matthews, indicating the following: "Do not test, rather teach, since the tests tell us what a person has learnt but tell us little about what the individual is capable of learning" (Gaddes, p. 268). It is on this concept of educational capacity and ability of an individual, that we base our position in this article. With regard to the developing of the curriculum and syllabus, some other authors having the teaching method approach to working with children with intellectual disabilities emphasize the importance of formulating the so-called "educational diagnosis". Accordingly, it is underlined that the development of individual syllabus for each individual child with intellectual disability requires precisely defined diagnostic strategies (Japundza-Milisavljevic et al., 2008).

With regard to the above, it is emphasized that educational diagnosis and teaching process are by no means separate and isolated activities. They are inseparably interconnected considering that educational diagnosis should be used whenever a special educator has the opportunity to observe and examine capabilities and behavior of children with intellectual disabilities. Considering that a student with intellectual disability who is included in education constitutes a continuous source of diagnostic information, and the development of individual curricula requires precise evaluation of each individual child, educational diagnosis is of key importance for successful implementation of treatment strategies.

According to these authors, educational diagnosis may be seen as a continuous assessment and evaluation of the development of a child with intellectual disability in terms of his/her relevant level of achievement in respect of each individual curricular requirement and task that was selected for them from the curriculum (Kail et al., 2007; MaćešićPetrović et al., 2009; Langdon et al., 2010).

This assessment of development and optimal achievement of a child in the educational process, rather than mere assessment of knowledge, should make up the essence of the education and treatment of children with intellectual disabilities. This relationship between development and achievement determines the term "educable" which, in our opinion, constitutes the essence of teaching methods when working with school age children with intellectual disabilities.

In accordance with the requirements of educational diagnostics, it is proposed to compile a diagnostic list or a questionnaire which should follow the curriculum so that children with intellectual disabilities could be assessed in accordance with the curriculum requirements set before them. This practically means that, if curricular requirements of initial education in the first grade envisages the development and exercise of auditory perception, for example then the child of that age is expected, within the overall repertoire of behaviors, to show a behavior which suggests the focusing of auditory attention towards the source of audio stimulus (head and eye movements towards the stimulus source) (MaćešićPetrović, 2010; Kovačević et al., 2010).

In such a case, the diagnostic list would, among others, have a question like this: - The child has this form of behavior: yes/no. In accordance with this, it is possible to develop this list in view of the needs for each individual teaching unit and course. With regard to this, it is pointed to the possibility to make valid assessments of the student's achievement based on the following formula:

$$
\mathrm{UNI}=\frac{\mathrm{BUI}}{\mathrm{PP}} \times 100=-\%
$$

SPL $=$ student's performance level, in percent NSP $=$ number of successfully performed activities $\mathrm{RN}=$ recommended number of observations/examinations (Macesic, Japundza-Milisavljevic, 2009). 
As stated by the authors, the number of recommended observations and/or examinations is 5 and, therefore, the above behavior associated with the auditory perception which appears in a child when mother tongue, for example, is taught, with the frequency of twice during the class, indicates the student's performance level of $40 \%$. The success criteria, according to the statements by these authors, cover the level of $80 \%$, which indicates that, in the domain of auditory perception in the students whose performance level is below $80 \%$, it is necessary to conduct an intensive rehabilitation treatment of auditory perception. The value of the above diagnostic list is reflected in the fact that in this way we can identify what a child with intellectual disability can do in the actual teaching situation rather than in the artificial environment of a test-situation.

In accordance with the proposed concept, we are here giving an overview of major strategies and techniques in assessment and treatment, which may be regularly used with children with intellectual disabilities.

\section{METHODOLOGY}

\section{Sample}

This research was conducted on a random sample of 124 examinees with mild intellectual disabilities, whose IQ ranges from 51 to 70 as assessed by WISC scale of intellectual abilities. Chronological distribution of the examinees ranges from 8 years of age to 13 years and 6 months due to the prolonged period of attendance of regular schools and the prolonged period of adaptation to the conditions of education. The sample includes the examinees who attend elementary schools in Belgrade from 2nd to 5th grade. The sample is equaled according to the level of education, since $25 \%$ from each class was chosen to be examined according to the prescribed criteria for choosing the examinees for the sample (both the age and the parameters significant for the outcome of the conducted research). Gender distribution is also included in the sample, with $39.5 \%$ of female and $60.5 \%$ of male examinees.
According to the characteristics of the socio-economic status, the majority of the examined children $(65.3 \%)$ falls into the category of the lower socioeconomic status. Also, the presence of bilingualism was noticed in $27.4 \%$ of the children, of whom $14.5 \%$ have mastered both languages equally well or badly (balanced bilingualism), while $12.9 \%$ have mastered one language better, mostly Romani or Albanian language (dominant bilingualism). All these factors, as characteristics of the examined sample which may influence the examined variables and achievements of the children on the applied test, are controlled within the wider research study and will not be shown here because of the spatial and conceptual limitation of the scope of the defined article.

\section{Method}

The method of neuropsychological diagnostics was applied in the article due to evaluation of the neuropsychological development of the examinees. We have also implemented the method of the standard analysis of the school documentation and surveying the teachers. Luria-Nebraska Battery for children (LNNB-C) was applied for assessing the reading, writing and match abilities (Golden, 1987). These clinical developmental scales assess neuropsychological processes from elementary to complex neuropsychological functions underlined in processes of reading, writing and match. Conner's Rating Scale (Gillberg, 1992) is implemented in estimating the behavior of the subjects of the sample and we assess their behavior in classroom in relation with their school achievement. The part examining behavior of a child in school situation was applied in our article since we have been interested in the relation between the educational situation and behavior of the children in the sample. It contains several subtests, and here we show the results of the application of Conners Rating Scale for teachers, which comprises areas of attention problems and hyperactivity. The statistical analysis of the obtained results are presented in numerical values, percents and Pearson's " $r$ " coefficient of correlation. 


\section{RESULTS}

As we mentioned before, here will be present the descriptive findings of cognitive and behavioral functioning of the tested children in our research.

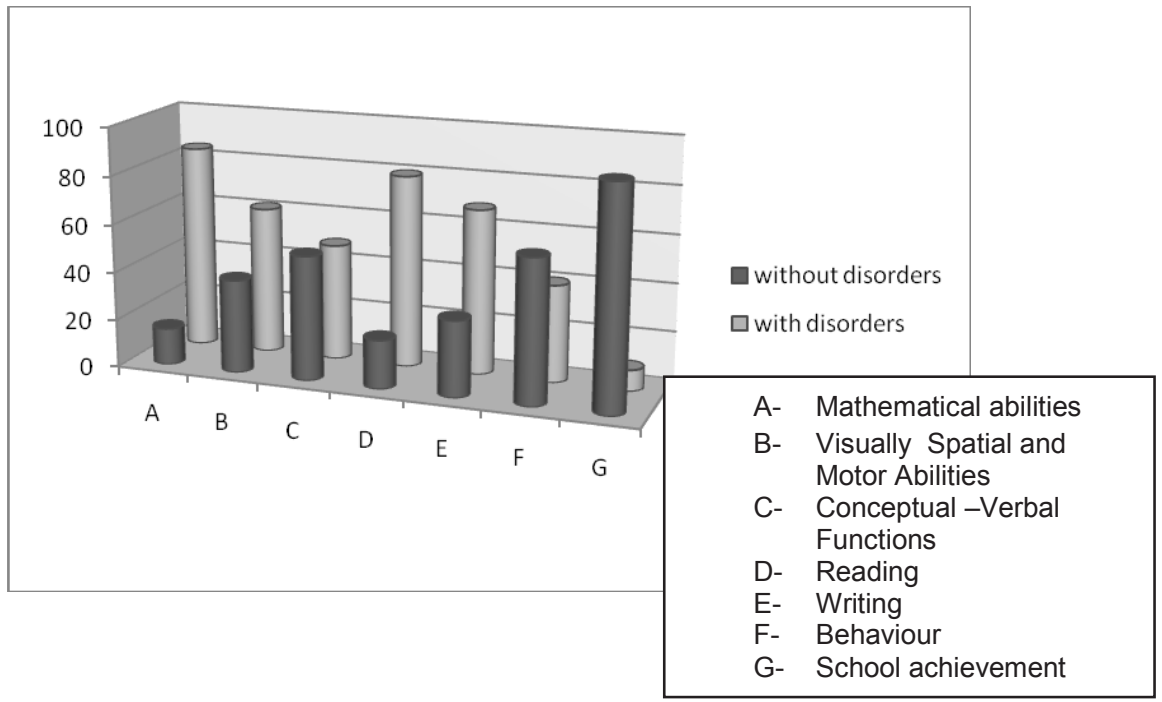

Figure 1-Results of the evaluation of the tested sample

As we can see from figure 1 , over $50 \%$ of the sample has developmental disabilities in tested developmental areas except in area of behavior. Almost $90 \%$ of the tested sample have problems in the tested area of the mathematical abilities. High percentage of the sample has shown problems in visual-spatial and motor abilities same as conceptual- verbal functioning (in the range from almost $80 \%$ to half of the sample-about $50 \%$ of participants). More than a half of the sample has manifested the problems of writing which is

Table 1 - School achievement of the tested sample important or significant sign of the cognitive deficits which has been shown in this research. On the base of these results we propose educational strategies based on the curricular requirements for defining the Individual Educational Program and Individual Training Program (IEP, ITP). In accordance with gained results we can conclude about the necessity of implementation of different aspects and forms of treatment in educational and rehabilitation settings for children with intellectual disabilities.

\begin{tabular}{|c|c|c|c|c|c|c|}
\hline & \multicolumn{2}{|c|}{ School achievement } & \multicolumn{2}{|c|}{$\begin{array}{c}\text { Success } \\
\text { in mathematics }\end{array}$} & \multicolumn{2}{|c|}{$\begin{array}{c}\text { Success } \\
\text { in maternal language }\end{array}$} \\
\hline & $\mathrm{N}$ & $\%$ & $\mathrm{~N}$ & $\%$ & $\mathrm{~N}$ & $\%$ \\
\hline Excellent & 34 & 27.4 & 35 & 28.2 & 36 & 29.1 \\
\hline Very good & 45 & 36.4 & 22 & 17.7 & 25 & 20.1 \\
\hline Good & 34 & 27.4 & 27 & 21.8 & 35 & 28.2 \\
\hline Satisfactory & 7 & 5.6 & 35 & 28.2 & 24 & 19.4 \\
\hline Unsatisfactory & 4 & 3.2 & 5 & 4.1 & 4 & 3.2 \\
\hline Total & 124 & 100 & 124 & 100 & 124 & 100 \\
\hline
\end{tabular}

The results point out that more than half of the participants achieved excellent (5), very good (4) and good (3) school achievement in the all of tested area of school subjects same as general school achievement. This is the result of promotion of stimulating func- tions of the school marks in education of the children with intellectual disabilities. In education the children with intellectual disabilities we try to avoid the frustrating school experiences which can be the risk factor for emotional and behavioral vulnerability of this children. 
Because of that we find more children with good school achievement than pupils with worse success sible appearing of emotional disturbances in school situation. in school. This is the primary prevention of the pos-

Table 2 - Results of statistical analysis

\begin{tabular}{cclllllc}
\hline Attention & $\begin{array}{l}\text { Mathematical } \\
\text { abilities }\end{array}$ & $\begin{array}{l}\text { Visually Spatial and } \\
\text { Motor Abilities }\end{array}$ & $\begin{array}{l}\text { Conceptual-Verbal } \\
\text { Functions }\end{array}$ & Read & Write & Behavior & $\begin{array}{l}\text { School } \\
\text { achievement }\end{array}$ \\
\hline $\mathrm{r}$ & 0.62 & 0.53 & 0.52 & 0.67 & 0.67 & 0.42 & 0.62 \\
$\mathrm{p}$ & 0.01 & 0.01 & 0.01 & 0.01 & 0.01 & 0.01 & 0.01 \\
\hline
\end{tabular}

The results of statistical analysis point out the high statistical significance between the tested variables $(\mathrm{p}<$ 0.01 ). These results obtained the relationship between voluntary attention and mathematical thinking structures, visual perception, spatial recognition and conceptual experience in relation with verbal functioning. The attention processes are formatting activities for the cognitive processes and academic achievement of the children with mild intellectual disabilities. Attention is also very important factor of shaping and formatting the quality of behavior in situation of education of the tested participants. The relationship between these tested variables are high statistically significant $(p<0.01)$. On the base of the obtained results we can conclude about the significance of the presence of the cognitive and cerebral disfunction, based on the cognitive problems, which depend of the knowledge of special educators about the principals of the cerebral organization and cognitive structure of the behavior. Interpretation of the results must be oriented from " behavior to brain" with respect of test performance which can be the base of the conclusion about the state of the whole functional brain system. Explanation of the deficits are based on the terminology of disorders of the functional systems.

\section{DISCUSSION}

As we can see from the obtained results there is a strong correlation between cognitive and behavioral functioning of the children with mild intellectual disabilities ( $p$ $<0.01$ ). It means that we can conclude on the base of the results from various studies that attention deficits with or without hyperactivity has strong influence on the thinking structures (conceptual formation), verbal functioning and communication in classroom, visually-spatial and motor functioning and especially at the reading, writing and mathematical abilities which finally product general school achievement of the school aged children with ID.
Strong influence of attention disorders on the behavior in classroom of the tested children has been confirmed by the results of statistical analyses $(p<0.01)$. These results are according with other research results in other scientific areas (Szymanski, Crocker, 1989; Craig, 2000; Došen, Kenneth, 2001; Kail, Ferrer, 2007; Conroy, Stichter, Daunic, Haydon, 2008; JapundžaMilisavljević, Maćešić-Petrović, 2008; MaćešićPetrović, Kovačević, Japundža-Milisavljević, 2009; Maćešić-Petrović, Kovačević, Hasanbegović, 2012).

\section{Treatment Strategies of applied research: curricu- lar requirements and contents for defining IEP and ITP}

In the light of applied research we propose the following curriculum contents for development of cognitive and behavioral functioning of the children with intellectual disabilities (Maćešić-Petrović, 1998).

\section{Visual-spatial perception}

Development of the skills of visual identification of familiar objects by naming;

Development of the skills of visual identification of familiar objects by naming;

Development of the skills of visal identification of the images of familiar objects by naming;

Development of the skills of detecting, recognizing and identifying shaded figures in images of different visibility levels;

Development of the skills of detecting, recognizing and identifying the figures on the images masked by covering the figures;

Development of the skills of identifying the correctness of the position of figures at the level of graph-motor space;

Development of the skills of graphical reproduction of figures from memory;

Development of the spatial gnosis directed towards engaging spatial rotation and transformation. 


\section{Elementary and complex motor functions}

Development of the differentiation of peripheral activities of upper psycho-motor activities (activities of the arms) - (development of the differentiated motor activities of fingers and speed of motor achievement);

Development of elementary motor activities of the hand and fingers without involvement of sight (development of somatognosis at the level of hand and fingers);

Development of visual-spatial organization at the level of subjective and objective space (development of the skills of detecting, recognizing and reproducing the position of items at the level of manipulative space in accordance with a given model);

Development of the final level of the awareness of body's entirety (development of the knowledge of lateralization of one's own and other person's body executive motor activities of cross orders);

Development of melokinetic praxis activities (development of alternate, alternative activities of upper extremities/hand, fist, fingers);

Development of melokinetic praxis activities at the level of graphical-motor skills (melokinetic praxis activities of execution of graphical-motor orders);

Development of praxis activities of oral and buccal musculature, and facial musculature;

Development of constructive-praxis activities of reproducing visually given models without rotation with a structure of sticks;

Development of constructive-praxis activities of reproducing visually given models with rotation with structure of sticks (structures oriented towards the development of representational levels and skills of mental rotation and transformation);

Development of constructive-praxis activities of reproducing given models by drawing and constructing pursuant to the verbal order (constructive praxis in the function of representational level development); Development of intellectual/motor activities of motor act verbal regulation.

\section{Conceptual-verbal functions}

Development of the skills of detection, discrimination (recognition) and naming of red items; Development of the skills of detection, discrimination (recognition) and naming of blue items;

Development of the skills of detection, discrimina- tion (recognition) and naming of yellow items; Development of the skills of detection, recognition and naming of green items;

Development of the skills of detection, recognition and naming of violet items;

Development of the skills of detection, recognition and naming of orange, brown, purple, grey, black, and white items;

Development of the skills of detection, recognition and naming of the colors of food.

Levels of the use of teaching aids include the use of specific items from the natural environment, artificial teaching aids in the form of didactic materials of different colors, followed by the use of pictures and photos of these items, application of items by the use of sticky pad, colored drawings on the board and in notebooks, etc.

The concept of equivalence according to the size and shape should be developed in initial phases through the detection of small, large and medium toys, items and objects from everyday life, and afterwards include familiar persons, places, foods, drinks, basic geometric shapes (circle, square, rectangle, etc.). The levels of use, according to what the authors have written in this area, include specific items, photographs, pictures, and drawings oriented towards symbolic presentation of these items.

The usable value of items and objects, and their interrelations, needs to be processed at two levels. The first level includes familiar and unfamiliar, namely favored and less favored objects in the form of specific items, activities, etc., while processed within the second level are words - names by which these items are designated.

\section{Mathematical concepts and abilities}

Results of the research in this area indicated that an extremely large number of subjects with mathematical reasoning disabilities and difficulties to master the teaching content of mathematics. Subjects in the oldest age and school grade are mostly failing as well. For these reasons, curricular content in the area of mathematics is not defined according to the school age (grade) but rather in the form of developmental requirements which should serve as the basis for definition of individual syllabus for each individual child with mild intellectual disabilities. 
Curricular content would be realized in the following order:

Development of skills to identify the numbers with different degree of complexity by naming them (reading the numbers of different degree of complexity, depending on developmental skills and needs of each individual child);

Development of skills to write numbers as dictated (single-cipher, two-cipher and/or three-cipher, depending on the skills of a child);

Development of skills to identify the numbers of different degree of complexity which are spatially organized from top to bottom, instead of from left to right (oriented on the development of comprehending the concept of the number and development of cognitive flexibility at the level of mathematical reasoning);

Development of skills of auditory comparison of the numbers of different degree of complexity according to the size;

Development of skills of visual comparison of the numbers of different degree of complexity according to the size;

Development of skills to add up numbers of different degree of complexity with and without noting them down;

Development of skills to subtract numbers of dif ferent degree of complexity with and without noting them down;

Development of skills to multiply single-cipher numbers (multiplication table).

\section{Writing abilities}

Development of skills to auditory identify the number of phonemes in words of different complexity level uttered by special educator (development of auditory discrimination and phonemic differentiation skills;

Development of skill to auditory identify the position of phonemes in the words of different complexity degree uttered by special educator;

Development of skill to copy the letters, words, and sentences after a given graphic model (printed and handwritten Cyrillic letters);

Development of skills to write one's own name and signature;

Development of skills to write letters as dictated;

Development of skills to write nonsensical syllables as dictated;

Writing words and sentences of different complexity degree as dictated.

\section{Reading abilities}

Development of skills of auditory synthesis of phonemes as the basis of nonsensical syllables and meaningful words;

Development of skill to naming (read) letters; Development of skill of phonemic analysis of proper nouns;

Development of skill to read nonsensical syllables of different complexity level;

Development of skill to read the words of different complexity level;

Development of skill to read the sentences of different complexity level;

Development of skill to read familiar and unfamiliar texts of different complexity level;

Development level of the skills included in the above curricular content may be assessed for each individual student according to the formula provided here in the part concerning the educational diagnosis.

\section{Social functioning skills in educational environ- ment}

Harmonious behavior in the classroom is characterized by the absence of bad temper, argumentative and irritable behavior and over-apprehension with the absence of destructivity and unpredictable behavior, and with the absence of propensity to lie or steal.

Behavior in the classroom with congruent development of willful attention should be characterized by congruent skills of movement coordination, attentiveness and capability of prolonged focus of attention, which enable the child to complete the commenced activities and prevent the propensity towards daydreaming.

Congruent development of attention also allows that behavior of the child is dominated by motor stability with the absence of motor anxiety, noise and disturbance of other children in group and individual activities. At the level of involvement in the group, noticeable in the children with congruent development of attention and behavior is the absence of gullibility and presence of capability to lead the group with the possibility of cooperation with other children and persons of authority.

Development of congruent socio-emotional functioning in the classroom (absence of the behavior form characterized by bad temper, argumentativeness and irritability, tearfulness, destructivity, unpredictability, and propensity to lie and steal). 
Development of movement coordination skills;

Development of willful attention;

Development of skill to complete the commenced activities;

Development of skills to get involved in different kinds of individual and group activities as the preventive basis for occurrence of daydreaming;

Development of motor stability and the stability of willful attention as the preventive basis of motor anxiety and disturbance of activities of the other children in the group; Development of skills to lead a group;

Development of a feeling for fair-play behavior in group activities;

Development of the activities of cooperation with other children in the group, of the same or opposite gender;

Development of the activities of cooperation with persons of authority (absence of the behavior pattern characterized by excessive submissiveness, impudence, inconsiderateness and stubbornness towards authority).

This part is particularly accentuating the need to synthesize the knowledge from the area of special education with the knowledge from child psychiatry and developmental neuropsychology as the basis of mental hygiene approach to the education of children with intellectual disabilities (Maćešić-Petrović, Kovačević, Hasanbegović, 2012). In this context we place the educational neuropsychology, seen through the application of theoretical and practical knowledge from the related scientific disciplines as well as through the application of educational diagnosis with the aim to define curricular content.

\section{CONCLUSION}

Bearing in mind that over the half of the tested children were unsuccessfully, in the area of the above mentioned interventions, we propose the treatment strategy and techniques from our environment. It has been known as method from French speaking countries as Reeducation Treatment of Psychomotor Activity-RTPA (Bojanin, 1986). This methodological and conceptual frame implies the use of speech, motor and perceptual exercise, team work and supervision of child psychiatrist, while the exercises should be led by a special educator and rehabilitation specialists. These exercises have to improve the following performances:

Reduce the motor and emotional impulsivity of the child; Reduce the distractibility of child's attention; Improve the cognitive strategies of the child; Improve learning strategies of the childImprove educational and self-educational strategies of the child, teacher and parents.
Specifically defined individual training program is offered for these developmental disorders. Such activities are based on:

Pharmacotherapy,

Behavioral therapy;

Pharmacotherapy and behavioral therapy combination Education of all persons involved in patient care activities, such as parents, teachers and children.

Presented results indicate the significance of multimodal oriented approach to cognitive and behavioral disorders of children with intellectual disabilities. This approach involves combination of various strategies designed in education and treatment of children and youth with intellectual disabilities, such as: team work of professionals and non- professionals, complementary treatment (special education and rehabilitation, psychosocial interventions, combination of treatment strategies), psychotherapy and psycho pharmacotherapy when necessary. As part of special education, individual educational programs and individual training programs (IEP and ITP), based on individual needs and abilities of children, are also being applied and defined.

The findings of this research have highlighted the need to introduce and develop various treatment strategies for children with cognitive and behavioral disorders. Based on the results of this study we can conclude about necessity to apply a complete multimodal approach that includes:

Development of the skills of detection, discrimination (recognition) and naming of red items,

Team work of professionals and non- professionals (child psychiatrists, special educators, teachers, parents);

Multimodal treatment which includes strategies of combined therapeutic approaches;

Complementary treatment (education, psychosocial intervention, combination of special education methods, such as reeducation of psychomotor activity etc.);

Psycho pharmacotherapy when necessary;

Individual educational programs (IEP);

Individual treatment programs (ITP) (Maćešić-Petrović, Kovačević, Hasanbegović, 2012).

Adaptation of the treatment must be focused on the developmental abilities of the child. Multidisciplinary approach includes psychopharmacological approach, psychotherapy with families and children with developmental disorders, as well as social work with environment and families. Therapeutic approaches such as sensory integration therapy (J. Ayres), Montesorry method, dance and movement therapy, music therapy etc., are also proposed when necessary. 


\section{REFERENCES}

Bailey, R. (2005). Evaluating the relationship between physical education, sport and social inclusion, Educational Review, 57:1, 71-90. Available on http://dx.doi. org/10.1080/0013191042000274196

Bojanin, S. (1986). Neuropsihologija razvojnog doba $i$ opšti reedukativni metod. Beograd: Zavod za udžbenike i nastavna sredstva.

Conroy, M. A., Stichter, J. P., Daunic, A.\& Haydon, T. (2008). Classroom-Based Research in the Field of Emotional and Behavioural Disorders: Methodological, The Journal of Special Education, 4, 209-222.

Craig, W. M. (2000). Childhood Social Development. London: Blackwell publishing.

Došen, A. \& Kenneth, D. (2001). Children and Adults with Intellectual Disability, Washington, DC, London, England.

Durston, S .\& Konrad, K. (2007). Integrating genetic, psychopharmacological and neuroimaging studies: A converging methods approach to understanding the neurobiology of ADHD. Developmental Review 27, 374-395.

Gaddes, H. W. (1985). Learning Disabilities and Brain Dysfunction - A Neuropsychological Approach, Springer Verlag, New York Inc.: New York.

Gillberg, C. (1992). European Child and Adolescent Psychiatry, Supplement No.1, Hogrefe \& Huber Publ.: New York.

Golden, C. J. (1987). Luria-Nebrasca Neuropsychological Battery: Children's Revision- Manual, WPS: Los Angeles.

Japundža-Milisavljević, M. \& Maćešić-Petrović, D. (2008). Executive Functions in Children with Intellectual Disabilities. The British Journal of Developmental Disabilities, 54 (107),
113-121.

Kail, R.V. \& Ferrer, E. (2007). Processing speed in childhood and adolescence: Longitudinal models for examining developmental change. Child Development, 6, 1760-1770.

Kovačević, J., Slavnić, S. \& Maćešić-Petrović, D. (2010). Treatment and speech-language development at the children with hearing impairments, Procedia Social and Behavioral Sciences, 5, 163-169.

Langdon, E. L., Clare, I.C.H. \& Murphy H. G. (2010). Developing an understanding of the literature relating to the moral development of people with intellectual disabilities. Developmental Review 30, 273 -293.

Maćešić-Petrović D. (1998). Mentalna retardacija-kognicija $i$ motorika. Beograd: Zadužbina "Andrejević".

Maćešić-Petrović D., Japundža-Milisavljević M. (2009). Diagnostic and rehabilitational approach to the education of the children with intellectual disabilities. Beogradska defektološka škola, 1, 149-156. http://scindeks.ceon.rs/article.asp

Maćešić-Petrović D., Kovačević J. \& Japundža-Milisavljević M. (2009). Learning activity in retarded children: neuropsychological aspects. Вопросы Психологии, 1, 32-37.

Maćešić-Petrović, D., Lazić, D., Japundža-Milisavljević, M., Djurić-Zdravković, A. (2010). Behavioral Disorders and Drug Therapy. The Open Conference Proceedings Journal, 1: 109114. doi: 10.2174/2210289201001010109

Maćešić-Petrović D., Kovačević J., Hasanbegović, H. (2012). Cognition, behavior, intellectual disabilities: Intervention strategies. HealthMED, 7 (6), 2563-2569.

Szymanski, L.S. \& Crocker A.C. (1989). Mental Retardation. In Comprehensive Textbook of Psychiatry/IV, eds. H.I. Kaplan and B.J. Sadock. Baltimore: Williams \& Wilkins. 